\title{
TRAJETÓRIAS DE HOMENS INFAMES: POLÍTICAS PÚBLICAS PENAIS E PROGRAMAS DE APOIO A EGRESSOS DO SISTEMA PENITENCIÁRIO NO BRASIL \\ TRAYECTORIAS DE HOMBRES INFAMES: POLÍTICAS PÚBLICAS PENALES Y PROGRAMAS DE APOYO A EGRESOS DEL SISTEMA PENITENCIARIO EN EL BRASIL \\ THE WAY OF INFAMOUS MEN: PENAL PUBLIC POLITICIES AND THE SUPPORT PROGRAMS TO THOSE EXITING THE PENITENTIARY SYSTEM IN BRAZIL \\ LES TRAJECTOIRES DES HOMMES INFÂMES: LES POLITIQUES PENALES ET LES PROGRAMMES D'ASSISTANCE AUX EX-DÉTENUS DU SYSTĖME CARCÉRAL BRÉSILIEN
}

DOI: 10.5533/1984-2503-20102505

\section{Ligia Mori Madeira}

\section{RESUMO}

O artigo investiga o apoio a egressos do sistema penitenciário no Brasil, a partir do estudo das produções legislativas, das políticas públicas e da criação de programas de apoio, surgidos no país, a partir da década de 1990. Seu foco principal de análise recai sobre a atuação e o papel dos programas de apoio nas trajetórias de vida de egressos. $O$ estudo parte da análise sobre a inserção, no Brasil, dos modelos de welfarismo penal e de Estado penal. Os programas de apoio revelam-se como espaços de mediação para pequenas conquistas: acesso à cidadania formal, aos meios de sobrevivência, como alimentação, transporte e vestuário, e à saúde. Em menor escala, as iniciativas permitem a inserção educacional e no trabalho, a partir de escassas e precárias, mas importantes concessões. Com relação aos egressos, suas trajetórias de vida revelam a existência de baixos níveis de capital econômico e cultural, responsáveis, na busca de sobrevivência, dinheiro fácil, aventura ou por fatalidade, pelo ingresso na criminalidade. Marcados pela experiência prisional e suas conseqüências, como a prisionização e o estigma, os egressos têm nos programas de apoio um local de construção de sociabilidade e de visibilidade. Outros elementos são responsáveis por ampliar as esperanças e oportunidades dos egressos, como a formação de redes, a conversão religiosa e o acesso ao trabalho. A passagem por programas de apoio implica em ganhos e frustrações. A temporariedade da condição de egresso, somada à temporariedade das próprias 
iniciativas, embora não permita inclusões sociais em sentido pleno, resulta em manutenções longe do crime e na redução do peso da condição de homens infames. Palavras-chave: welfarismo, Estado penal, egressos do sistema penitenciário, redes sociais, inclusão e exclusão social.

\section{RESUMEN}

El artigo investiga el apoyo a egresos del sistema penitenciario en el Brasil, a partir del estudio de las producciones legislativas, de las políticas públicas y de la creación de programas de apoyo, surgidos en el país, a partir de la década de 1990. Su foco principal de análisis recae sobre la actuación y el papel de los programas de apoyo en las trayectorias de vida de egresos. El estudio parte del análisis sobre la inserción, en el Brasil, de los modelos de welfare penal y del Estado penal. Los programas de apoyo se revelan como espacios de mediación para pequeñas conquistas: acceso a la ciudadanía formal, a los medios de supervivencia, como alimentación, transporte y vestuario, y a la salud. En menor escala, las iniciativas permiten la inserción educacional y en el trabajo, a partir de escasas y precarias, pero importantes concesiones. Con relación a los egresos, sus trayectorias de vida revelan la existencia de bajos niveles de capital económico y cultural, responsables, en la búsqueda de supervivencia, dinero fácil, aventura o por fatalidad, por el ingreso en la criminalidad. Marcados por la experiencia de la prisión y sus consecuencias, como la prisionización y el estigma, los egresos tienen en los programas de apoyo un local de construcción de sociabilidad y de visibilidad. Otros elementos son responsables por ampliar las esperanzas y oportunidades de los egresos, como la formación de redes, la conversión religiosa y el acceso al trabajo. El pasaje por programas de apoyo implica en ganancias y frustraciones. La temporalidad de la condición de egreso, sumada a la temporalidad de las propias iniciativas, aunque no permita inclusiones sociales en sentido pleno, resulta en manutenciones lejos del crimen y en la reducción del peso de la condición de hombres infames.

Palabras-claves: welfare penal, egresos del sistema penitenciário, redes sociales, inclusión y exclusión social.

\section{ABSTRACT}

The paper aims at studying the support granted to ex-convicts of the Brazilian penitentiary system based on legislative productions, public policies and programs from the 90's 
onwards. It focuses mainly on the performance and role of support programs in relation to the life trajectory of ex-convicts. Also, the life trajectory and the impact of support programs were analyzed from the viewpoint of ex-convicts. This study also highlights the insertion of the Penal Welfarism model and the Penal State model in Brazil. In the light of public and social theories, the support programs examined showed mediation spaces to the rising of small victories: access to formal citizenship, food, means of transportation, clothing and health. Although in a smaller scale, the initiatives also granted educational and work insertion. Notwithstanding, the life trajectories of ex-convicts reveal the existence of low economic and cultural capital levels which, in the struggle for survival, may lead to crime. Once entering the prison system and experiencing its consequences such as prisioning and stigma, the ex-convicts rely on the support programs to help rebuild their sociability and visibility. Moreover, there are other elements responsible for broadening the hope and opportunities of such people, for instance, the formation of social networks, religious conversion and work access. On the other hand, attending a support program involves victories and frustrations. Furthermore, the stigma of being an ex-convict and the temporality of initiatives might not bring full social inclusion, but they certainly help keep these people from committing crimes and help lessen the stigma of infamous men.

Key-words: penal welfarism, penal state, ex-convicts from the penitentiary system, social networks, social inclusion and exclusion.

\section{RÉSUMÉ}

L'article analyse le soutien donné aux ex-détenus du système carcéral brésilien, à partir de l'étude des productions législatives, des politiques publiques et de la création de programmes d'assistance sociale, créés au Brésil, depuis les années 1990. Son objet principal d'analyse repose sur la portée et le rôle des programmes de soutien dans les trajectoires de vie des ex-détenus. L'étude part d'une analyse sur l'insertion au Brésil des modéles de bien-être pénal et de l'Etat pénal. Les programmes d'assistance se présentent comme des espaces de médiation pour les petits gains : l'accès à la citoyenneté formelle, aux moyens de survivance tels que l'alimentation, le transport, le vêtement et aux soins de santé. À petite échelle, les initiatives permettent l'accès à l'éducation et au marché du travail, à partir de rares et précaires concessions mais dont l'importance est majeure. En ce qui concerne les ex-détenus, leurs trajectoires de vie révèlent l'existance d'un faible niveau de capital économique et culturel, responsables par leurs débuts dans la 
criminalité, à la recherche d'une survie, d'argent facile, d'aventure, ou par fatalité. Marqués par l'expérience carcérale et ses conséquences, les ex-détenus ont dans les programmes d'assistance un lieu de construction de sociabilité et de visibilité. D'autres elements sont responsables par la poussé de l'espoir et des opportunités des ex-détenus, comme la création des réseaux sociaux, la conversion religieuse et l'accès au travail. Le passage par des programmes d'assistance apporte des victoires et des frustations. La temporalité de la condition d'ex-détenu, ajoutée à la temporalité de leurs propres initiatives, arrive à les mantenir eloignés du crime et à reduire le fardeau de la condition d'être un homme infâme, même sans permettre une intégration au sens plein.

Mots-clés : bien-être penal, Etat penal, ex-détenus du système carcéral, reseaux sociales, inclusion et exclusion sociale.

\section{Introdução}

Este artigo busca empreender uma análise acerca das políticas públicas penais, no que diz respeito à formulação, implementação e atuação de programas de apoio públicos e da sociedade civil, destinados a auxiliar egressos do sistema penitenciário brasileiro em seu retorno à sociedade. Com relação aos egressos, foram investigadas trajetórias de vida, considerando o peso do aprisionamento, o impacto da passagem por tais iniciativas e suas chances de reinserção na sociedade.

Inserido na área de sociologia da violência e criminalidade, este tema faz parte de novos estudos prisionais, ainda escassos no Brasil, voltados à investigação de egressos do sistema penitenciário ${ }^{1}$, tratados como categoria de estigmatizados ${ }^{2}$ e prisionizados ${ }^{3} \mathrm{em}$ uma sociedade excludente ${ }^{4}$, especialmente entre aqueles que pertencem às camadas mais desfavorecidas da população.

\footnotetext{
${ }^{1}$ LIEBLING, Alison; MARUNA, Shadd (2005). The effects of imprisonment. Londres: Willan Publishing; PETERSILIA, Joan (2003). When prisioners come home: parole and prisioners reentry. Oxford.

${ }^{2}$ GOFFMAN, Erving (1988). Estigma: Notas sobre a manipulação da identidade deteriorada. 4. ed. Rio de Janeiro: LTC.

3 BARATTA, Alessandro (1999). Criminologia crítica e crítica do direito penal: introdução à sociologia do direito penal. 2. ed. Rio de Janeiro: Freitas Bastos: Instituto Carioca de Criminologia; BORÉS ESPÍ, Josep García (2003). El impacto carcelario. In: BERGALLI, Roberto (coord.). Sistema Penal e problemas sociais. Valência: Tirant lo blanch.

${ }^{4}$ GARLAND, David (2005). El cultura del control. Barcelona: Editorial Gedisa; WACQUANT, Loïc (2001). As prisões da miséria. Rio de Janeiro: Jorge Zahar; WACQUANT, Loïc (2003). Punir os pobres. A nova gestão da miséria nos Estados Unidos. Rio de Janeiro: Revan; YOUNG, Jock (2002). A sociedade excludente. Rio de Janeiro: Revan: Instituto Carioca de Criminologia; CHRISTIE, Nils (2003). L'industrie de la Punition: prision et politique pénale em occident. Paris: Autrement.
} 
O artigo está estruturado da seguinte forma: em primeiro lugar apresenta-se o referencial teórico do estudo, passando às discussões metodológicas. Em segundo lugar, trata-se do contexto de surgimento e do desenvolvimento de programas de apoio e de políticas públicas penais para egressos do sistema penitenciário no Brasil. Em terceiro, discute-se a atuação dos programas de apoio, seguida da apresentação sobre a clientela dos programas, a partir da análise de trajetória de vida de egressos, enfocando aspectos como as marcas da prisão, o papel da religião, das redes e do trabalho. Por fim, questiona-se sobre as esperanças e oportunidades de inclusão para ex-presidiários no Brasil.

\section{Referencial teórico e metodologia}

O referencial teórico está estruturado em dois blocos: o primeiro tem por base conceituações de políticas públicas, políticas sociais e políticas penais ${ }^{5}$, voltadas à compreensão das políticas e programas de apoio para egressos do sistema penitenciário. O segundo está voltado a compreender os egressos, utiliza-se de referenciais como trajetória de vida, capital social, esperanças e oportunidades ${ }^{6}$; disciplinamento ${ }^{7}$, prisionização $^{8}$ e estigma ${ }^{9}$ para analisar sua passagem pela prisão; e inclusão/exclusão,

\footnotetext{
${ }^{5}$ HÖFLING, Eloísa de Mattos (2001). Estado e políticas (públicas) sociais. In: Cadernos Cedes, ano XXI, n. 55, novembro, p. 30-41; DELMAS-MARTY, Mireille (2004). Os grandes sistemas de política criminal. Barueri: Manole, 2004; ADORNO, Sérgio (1991). Sistema penitenciário no Brasil. Problemas e desafios. In: Revista USP: São Paulo, março, abril, maio, pp. 65-78; BEATO F., Cláudio (1999). Políticas Públicas de Segurança: equidade, eficiência e accountability. In: Reforma do Estado e Mudança Institucional no Brasil. Recife: Fundação Joaquim Nabuco e Editora Massangano, v.1, p. 335-365. Disponível em: http://www.crisp.ufmg.br/polpub.pdf. Acesso em 01/04/2008; SOUZA, Celina (2007). Estado da arte da pesquisa em políticas públicas. In: HOCHMAN, Gilberto; ARRETCHE, Marta; MARQUES, Eduardo. Políticas públicas no Brasil. Rio de Janeiro: Fiocruz, p. 65-86.

${ }^{6}$ BOURDIEU, Pierre (1980). Le sens pratique. Paris: Minuit; BOURDIEU, Pierre (1990). Coisas ditas. São Paulo: Brasiliense; BOURDIEU, Pierre (2001). Meditações pascalianas. Rio de Janeiro: Bertrand Brasil; BOURDIEU, Pierre (1999). O capital social - notas provisórias. In: NOGUEIRA, Maria Alice; CATANI, Afrânio. Pierre Bourdieu: escritos de educação. 2. ed. Petrópolis: Vozes, p. 65 - 70; BORDIEU, Pierre (2005). Esboço de auto-análise. São Paulo: Companhia das letras; BOURDIEU, Pierre (1997). Razones prácticas: sobre la teoría de la acción. Barcelona: Anagrama; BOURDIEU, BOURDIEU, Pierre (1996). A ilusão biográfica. In: In: AMADO, Janaína, FERREIRA, Marieta de Moraes. Usos e abusos da História Oral. Rio de Janeiro: Fundação Getúlio Vargas, p. 183-191.

7 FOUCAULT, Michel (1996). La vida de los hombres infames. La Plata: Caronte Ensayos; FOUCAULT, Michel (2003). Ditos e escritos IV. Estratégia, poder-saber. Rio de Janeiro: Forense Universitária; FOUCAULT, Michel (2002). Os anormais. São Paulo: Martins Fontes; FOUCAULT, Michel (1996). Vigiar e Punir. História da violência nas prisões, $14^{\mathrm{a}}$ ed.. Petrópolis: Vozes.

${ }^{8}$ BORÉS ESPÍ, Josep García (2003). El impacto carcelario. In: BERGALLI, Roberto (coord.). Sistema Penal e problemas sociais. Valência: Tirant lo blanch.

${ }^{9}$ GOFFMAN, Erving (1988). Estigma: Notas sobre a manipulação da identidade deteriorada. 4. ed. Rio de Janeiro: LTC.
} 
discutindo o papel das redes sociais, da religião e do trabalho para a investigação acerca de suas possibilidades pós-prisionais ${ }^{10}$.

O artigo foi construído a partir da análise em profundidade de quatro programas existentes no Brasil: Agentes da Liberdade, no Rio de Janeiro, Pró-egresso, de MaringáPR, Programa de Acompanhamento Social (PAS) e a Fundação de Apoio ao Egresso do Sistema Penitenciário (Faesp), ambos em Porto Alegre.

A escolha dos quatro programas acima para uma pesquisa em profundidade deveuse a vários fatores: em primeiro lugar, tentou-se dar conta do tipo de apoio despendido a egressos, se público ou da sociedade civil, sendo assim, foram escolhidos um programa público desenvolvido pelo Poder Judiciário (PAS), um programa público atrelado ao Poder Executivo Municipal (Agentes da Liberdade), um programa considerado misto, realizado como extensão universitária de uma Universidade Pública (Pró-egresso), em convênio com a Secretaria de Estado da Justiça do Paraná, mas operacionalizado via Poder Judiciário, e um programa da sociedade civil (Faesp), não dispensando, para sua atuação, o apoio do setor público. A escolha também foi definida em termos do tempo de funcionamento dos programas: o Pró-egresso desenvolvia atividades há mais de 20 anos, enquanto os demais foram criados no final da década de 1990 e início de 2000 . A escolha dos quatro programas foi decorrente da disponibilidade de acesso a dados e entrevistados. Sendo assim, com exceção da Chefia de Apoio a Egressos e Liberados (Cael), de Recife - que disponibilizou acesso a todo o material, em uma visita ${ }^{11}$ realizada em termos exploratórios -, os demais programas participantes do estudo exploratório ${ }^{12}$ não se mostraram muito abertos a uma investigação empírica. Por fim, como uma última justificativa, as informações, fornecidas em estudo exploratório, pelos programas selecionados, despertaram uma grande curiosidade, pela aparente efetividade, bem como pela abrangência numérica na atuação do apoio a egressos.

Os programas foram analisados em função de suas peculiaridades, apesar de as propostas e objetivos serem similares em todas as iniciativas. A atuação dessas iniciativas foi captada mediante a análise de conteúdo e o método comparativo. Os

${ }^{10}$ CASTEL, Robert (2001). As metamorfoses da questão social: uma crônica do salário, 3ª ed. Petrópolis: Vozes; XIBERRAS, Martine (1996). As teorias da exclusão: para uma compreensão do imaginário do desvio. Lisboa: Instituto Piaget; BARNES, J (1987). A. Redes sociais e processo político. In: FELDMANBIANCO, Bela (Org.). Antropologia das sociedades contemporâneas: métodos. São Paulo: Global, p. 159 223; QUIROGA, Ana Maria (2005). Religiões e Prisões no Rio de Janeiro: presença e significados. In: Comunicações do ISER, Rio de Janeiro, v. 61, n. 61, p. 13-21.

${ }_{11}^{11}$ Visita realizada em julho de 2004.

${ }^{12}$ Realizou-se um levantamento nacional da existência de programas de apoio a egressos que concluiu pela existência de 27 programas no país. 
programas foram comparados entre si em termos de efetividade em suas atuações no cumprimento das legislações penais. Seus cotidianos e seus documentos (prontuários de egressos, resoluções, regimento interno, estatutos, relatórios de atividades) também foram investigados.

Às coordenações dos respectivos programas foram aplicadas entrevistas semiestruturadas. Dentre os aspectos levantados, ressalta-se: proposta; operacionalização e funcionamento; beneficiários; avaliações, dificuldades e perspectivas. As entrevistas semiestruturadas aplicadas aos técnicos buscaram identificar o desenvolvimento da atividade de atendimento e apoio a egressos, a avaliação dessa população (facilidades e dificuldades) e as impressões acerca do programa e sua efetividade.

Posteriormente, investigou-se os ex-presidiários como categoria social, através de entrevistas de análise das trajetórias de vida: familiar (família na infância, família e criminalidade, família atual); educacional (escolaridade, percepção da escola e do ensino); profissional (trabalho, profissionalização, experiência laboral); aspectos culturais (religião e conversão religiosa); criminal (tipo de crime, motivação); prisional (punição, pena, prisão, trabalho e estudo prisional, estigma, prisionização); pós-prisional (família, trabalho, estudo hoje, a participação no programa, reinserção social).

Os egressos foram selecionados a partir de uma amostra que considerou a disponibilidade de tempo e o interesse em participar da pesquisa. Não foram considerados critérios como tipo de crime cometido, cor, religião, inserção ou não no mercado de trabalho. Tendo em vista o critério de saturação da amostra, não se estabeleceu números em função do universo de população atendida em cada programa, levou-se em conta, no entanto, as contribuições e originalidades de cada conversa, na medida em que permitiam lançar um olhar geral sobre a categoria social, e, ainda, dando conta das especificidades relativas às cidades, aos perfis criminais e às experiências de vida.

Os programas de apoio e as políticas públicas penais para egressos do sistema penitenciário no Brasil 
Partindo da premissa ${ }^{13}$ de que a temática da política criminal não pode ser compreendida fora do âmbito do Estado no qual está inserida, para a investigação do objeto de estudo deste artigo foi necessário analisar as duas principais fases de constituição do Estado moderno do pós-guerra. A primeira fase foi constituída pelo surgimento do "welfare state", modelo no qual surge o welfarismo penal, uma política criminal baseada no ideal de reabilitação, a partir do uso da prisão, seguindo-se pela crise do modelo, marcada pela descrença no papel do Estado e de seus mecanismos de controle social no gerenciamento da sociedade como um todo, e da criminalidade. A segunda fase, pós-crise, marcada pelas reformulações do Estado e, no âmbito penal, pela substituição da política de welfarismo pelo chamado Estado penal, no qual se decreta a falência do ideal de reabilitação e do uso tradicional dado à prisão, substituindo e ampliando sua utilização como um mecanismo de controle social voltado às categorias expulsas do sistema produtivo.

Essa discussão foi importante, na medida em que forneceu subsídios necessários para pensar a configuração do Estado brasileiro no que tange à sua forma, estrutura e modelo em termos de políticas públicas e sociais, e, mais especificamente, no que tange à política criminal. Sendo assim, sustentando-se que em meados dos anos 1980 o Brasil busca uma inserção no modelo criminal do welfarismo penal, com a promulgação, em 1984, da Lei de Execuções Penais (LEP) ${ }^{14}$, interessou-nos conhecer o desenvolvimento de uma preocupação com egressos do sistema penitenciário.

Visando incorporar os regramentos internacionais de proteção aos direitos humanos, especialmente as Regras Mínimas de Tratamento dos Reclusos, editadas pela ONU, em 1957 e $1977^{15}$, essa legislação, fruto de uma reforma penal promovida na parte geral do Código Penal de 1940, trata da pena de prisão como uma instituição falida; em consequência, são propostas uma série de alternativas para sanar sua ineficiência no que tange aos índices de reincidência e aos problemas vivenciados intramuros. Como uma tentativa de humanização do sistema penitenciário, são concedidas legalmente uma série de garantias aos presos: assistência material, educacional, social, religiosa e à saúde.

\footnotetext{
${ }^{13}$ Tal premissa teórica é herança de leituras críticas no âmbito da criminologia e da sociologia. Tomamos o modelo analítico de autores como Rusche e Kirchheimer, Garland, De Giorgi, Wacquant, que pressupõem a compreensão dos aspectos penais de uma sociedade conectada com seus modelos mais amplos, seja de estrutura econômica, seja de estrutura política.

${ }_{15}^{14}$ Lei $\mathrm{n} .7210$ de 11 de julho de 1984.

15 ONU, Organizações das Nações Unidas. Regras Mínimas para o Tratamento dos Reclusos, 1977. Disponível em: http://pfdc.pgr.mpf.gov.br/legislacao-pfdc/docs sistem-prisional/regras minimas.pdf. Acesso em 29/09/2008.
} 
Entre esses direitos, o trabalho e a educação são, na visão legal, primordiais. O trabalho é entendido como dever social e condição de dignidade humana, tendo finalidade educativa e produtiva. Tais direitos, de responsabilidade do Estado objetivam "prevenir o crime e orientar o retorno à convivência em sociedade", um objetivo claro da perspectiva teórica do welfarismo penal.

Reproduzindo no âmbito da legislação federal os regramentos internacionais de proteção aos reclusos, aparece, pela primeira vez, a preocupação com egressos do sistema penitenciário, conceituados pelo art. 26 como: "I - o liberado definitivo, pelo prazo de 1 (um) ano a contar da saída do estabelecimento; II - O liberado condicional, durante o período de prova”. Os egressos da prisão, durante o período estipulado acima, passam a ser beneficiários das mesmas garantias que os presos, por previsão do parágrafo único do art. 10 da LEP: "a assistência estende-se ao egresso".

Apesar da obrigatoriedade legal, a efetivação da LEP, a partir da formulação de políticas públicas focalizando egressos só irá ocorrer em meados da década de 1990, quando, por iniciativa dos poderes públicos estaduais e municipais, e da sociedade civil através da atuação de universidades, cooperativas, fundações e ONGs -, são implementados programas que visam à reinserção social de ex-presidiários, com uma atuação baseada no tripé: trabalho, escolarização-profissionalização e saúde.

No final da década de 1990, duas iniciativas acabam reforçando a criação desses programas: em 1997 a Igreja Católica lança a Campanha da Fraternidade com o tema "A Fraternidade e os Encarcerados", incentivando a participação da sociedade; a partir de 2000 o Ministério da Justiça e a Secretaria Nacional de Segurança Pública passam a conceder financiamento público para o desenvolvimento de projetos de redução da violência.

A implementação desses programas nos âmbitos estadual e municipal desperta o interesse em âmbito federal, em órgãos do Ministério da Justiça, como o Conselho Nacional de Política Criminal e Penitenciária (CNPCP) e a Secretaria de Reinserção Social, do Departamento Penitenciário Nacional (Depen), ambos preocupados em desenvolver uma política mais abrangente de apoio a egressos em todo o país ${ }^{16}$.

No âmbito do Poder Executivo Federal, tal preocupação deu origem a práticas denominadas ações de reinserção social: um conjunto de intervenções técnicas, políticas

16 Esses órgãos emitem uma série de resoluções incentivando a criação e a manutenção dos programas de apoio a egressos nas unidades da federação, bem como sugerindo o desenvolvimento de relatórios sobre tais práticas, sob a responsabilidade dos Conselhos Penitenciários Estaduais. 
e gerenciais levadas a efeito durante e após o cumprimento de penas ou medidas de segurança, no intuito de criar interfaces de aproximação entre Estado, comunidade e pessoas beneficiárias, como forma de lhes ampliar a resiliência e reduzir a vulnerabilidade frente ao sistema penal ${ }^{17}$.

Criados em nível estadual e municipal, os programas de apoio são fruto de constatações a respeito da falência da pena de prisão e do modelo monopolizador de Estado, que passa a ser visto como incapaz de, sozinho, dar conta do problema da criminalidade, da violência e especialmente da reincidência criminal.

A partir de atuações dos poderes públicos e da sociedade civil, desenvolvidos pelos poderes Executivos, Judiciário, prefeituras, universidades, cooperativas, fundações e ONGs, os programas de apoio visam à reinserção social de egressos e a redução dos índices de reincidência. Para tanto, atuam baseados nos ditames da LEP no que diz respeito à concessão de apoio a trabalho, educação e saúde.

\section{A atuação dos programas de apoio a egressos do sistema penitenciário}

O estudo realizado sobre os programas de apoio a egressos do sistema penitenciário - PAS, em Porto Alegre, e Agentes da Liberdade, no Rio de Janeiro, caracterizando-se como públicos; e Pró-Egresso, em Maringá, e Faesp, em Porto Alegre, como programas da sociedade civil -, revelou a existência de objetivos similares, como a busca de reinserção social pelo trabalho, o encaminhamento para as redes públicas de saúde, educação e assistência social, bem como a preocupação com a redução da reincidência.

Buscando a inclusão de egressos, os programas desenvolvem atividades para a conquista de cidadania formal, promovendo o acesso a documentos; auxílio à sobrevivência, através de doações de alimentos, roupas e calçados e vales-transporte; acesso à saúde; bem como atividades visando à qualificação e à colocação no mercado de trabalho.

Os programas contam com um corpo técnico geralmente constituído por assistentes sociais, psicólogos e advogados. O tempo de permanência dos egressos no programa varia muito em cada programa: enquanto o programa de Maringá fiscaliza as penas pelo tempo estipulado na sentença judicial, o programa carioca atende por um período pré-

\footnotetext{
${ }^{17}$ BRASIL, Ministério da Justiça. Manual de convênios e projetos de reintegração social. Brasília: DEPEN, 2005.
} 
determinado de três meses, e os programas de Porto Alegre não estipulam tempo de duração, mantendo os egressos vinculados e prestando auxílio quando há necessidade.

O perfil dos beneficiários dos programas coincide: são preferencialmente homens; solteiros, apesar de terem filhos e, muitas vezes, com uniões estáveis informais constituídas; com idades e escolaridades baixas; com uma grande representatividade negra (encontrada, obviamente, no caso do Rio de Janeiro, mas sobrerrepresentada no caso de Porto Alegre); condenados - pela prática de crimes contra o patrimônio (roubo e furto), de entorpecentes, homicídios ou sexuais - a penas médias; com índices relativamente baixos de reincidência (por volta dos 30\%); desempregados ou trabalhando na informalidade; em ocupações desqualificadas; sem renda ou com renda insuficiente.

Os quatro programas são fruto da constatação da falência da prisão e da impossibilidade de sobrevivência para aqueles que, sem qualquer auxílio, saem dela e devem manter-se afastados do crime. No entanto, há diferenças entre as atuações estatais e não-estatais: embora todos os programas estejam pautados pelos ditames da Lei de Execuções Penais, dependendo do caráter e do grau de fiscalização sobre o programa, há, nos discursos sustentadores, ora uma preocupação exclusiva com egressos e seu bem-estar (PAS, Agentes da Liberdade), ora uma atuação focalizando-os, mas justificada pelos benefícios sociais que reduções nos níveis de criminalidade possam trazer (Faesp, Pró-Egresso). Portanto, apesar de a função dos programas ser reinserir socialmente ex-presidiários, há diferenças entre programas que privilegiam como meta a redução da reincidência (Pró-Egresso, Faesp), e programas mais voltados a ganhos em termos de cidadania (PAS, Agentes da Liberdade).

Os programas contam, para o seu funcionamento, com o estabelecimento de determinadas redes constituídas por entidades públicas e privadas, que contribuem no fornecimento de materiais, vagas de trabalho e de educação, e provisões. Não obstante, sempre há, por parte das entidades, receio no estabelecimento dessas parcerias, pois temem auxiliar uma clientela constituída por ex-presidiários. Embora esses convênios existam, o financiamento das iniciativas é, na maioria das vezes, fruto de verbas públicas que, fornecidas por órgãos centrais, acabam sendo gerenciadas por entidades locais ou mesmo não-públicas. Além disso, todos os programas acabam permitindo a formação de redes de egressos, consideradas como fundamentais para a garantia de manutenção dos egressos longe da criminalidade. 
É preciso demonstrar os aspectos positivos e negativos do apoio promovido pelas iniciativas. Como aspectos positivos, embora os programas sustentem o fato de suprirem lacunas na atuação estatal, seja de descasos prisionais, seja por dificuldades dos poderes Judiciário e Executivo em realizarem suas atribuições; de serem iniciativas financeiramente viáveis, pelo dispêndio baixo de recursos; bem como terem atuações que resultam em redução de reincidência; acreditamos que há aspectos ainda mais importantes.

O primeiro deles diz respeito à constituição de redes sociais, seja de instituições, seja de egressos, que são fundamentais para a atuação voltada a ex-presidiários, e se apresentam como a única alternativa de garantir sobrevivência para essas populações em vulnerabilidade. As redes institucionais permitem o acesso à saúde, à educação e ao trabalho, mas são as redes de egressos, cuja formação é propiciada pelo espaço disponibilizado pelos programas de apoio, que são imprescindíveis como forma de construção de novas perspectivas de vida, de sociabilidade, de conquista de cidadania e inclusão.

O segundo aspecto de grande importância diz respeito à própria construção de visibilidade desta categoria social, que é formada a partir da criação dos programas de apoio. As iniciativas acabam por constituir um grupo social e dar-lhe visibilidade, o que é fundamental para a implementação de novas medidas, políticas e ações.

Com relação aos aspectos negativos, todos os programas salientam as dificuldades em focalizar um grupo completamente carente de recursos e auxílios. Além disso, todos os programas veem nas condições dos egressos problemas a serem enfrentados, seja no aspecto relacionado às experiências e marcas prisionais, como estigmatização, prisionização e perda de identidade, seja com relação a seu perfil desqualificado, em termos profissionais e educacionais.

No entanto, há outros aspectos restritivos na atuação dos programas de apoio. O primeiro deles refere-se à temporariedade: assim como o atendimento aos egressos é temporário, muitas iniciativas também têm uma existência temporária, especialmente aquelas que são fruto de convênios ou de projetos que precisam de renovação anual, ou estão sujeitas a poder discricionário dos agentes ou órgãos a que estão atreladas.

O segundo aspecto que precisa ser salientado refere-se à insuficiência de vagas, frente a um universo em constante crescimento. É preciso analisar a atuação dos programas de apoio relacionada às tendências da política criminal contemporânea e ao 
surgimento do Estado penal, que no Brasil será responsável pela ampliação crescente das vagas e do número de presos, o que levará a um déficit cada vez maior dos programas, que já atingem hoje uma parcela pós-prisional insignificante do ponto de vista quantitativo.

Além disso, é preciso questionar, relacionando as atuações com as tendências atuais da política criminal, o quanto as iniciativas estão inseridas em uma lógica de controle social e gerenciamento do risco, que teria por consequência a manutenção longe do crime por parte dos egressos apoiados.

\section{A clientela dos programas: egressos do sistema penitenciário em trajetória}

Nesse estudo foi feita a apropriação de um termo jurídico, que está relacionado a um modelo criminológico, conectado a modelos de Estado social, que crê na ressocialização e inserção social a partir da atuação das agências formais de controle criminal. Assim, só há egressos no contexto de uma concepção de integração social: o termo egresso é um conceito jurídico-legal presente no artigo 26 da Lei de Execuções Penais. Explorando historicamente o surgimento e o desenrolar da proteção aos oriundos do cárcere, percebe-se que o paradigma criminológico por trás de tal preocupação é o welfarismo penal. A discussão sobre a atuação de políticas sociais e penais e de programas de apoio a ex-presidiários é parte de um discurso recuperador/ressocializador e a tônica por trás da existência de uma preocupação com pessoas oriundas da prisão é salvacionista ${ }^{18}$. Não existem egressos fora de uma concepção welfarista.

Para além do aspecto legal, buscou-se compreender esses indivíduos como uma categoria sociológica, percebendo os ex-presidiários como sujeitos cuja passagem pela prisão é uma marca coletiva que define suas trajetórias de vida, da mesma forma que carências materiais, familiares, infra-estruturais definiram suas trajetórias até a vida criminal. Partiu-se do pressuposto de que a trajetória é fundamental por marcar a constituição do egresso, estando ligada a habitus e capitais como heranças determinantes na construção das posições no espaço social. Além disso, sustenta-se que a existência de categorias como estigma, religião, redes e trabalho definem essas trajetórias, tornando-os passíveis de investigação como grupo social.

A fim de conhecer tais trajetórias de vida, investigou-se grupos de ex-presidiários que se constituíram em clientela dos programas analisados nas cidades de Porto Alegre e

18 MORAES, Pedro Rodolfo Bode de (2005). Punição, encarceramento e construção de identidade profissional entre agentes penitenciários. São Paulo: IBCCRIM. 
Rio de Janeiro, buscando realizar, como bem explicita Castro ${ }^{19}$ "uma interpretação sociológica da perspectiva de vida de egressos do sistema penitenciário".

As trajetórias de vida dos egressos no Rio de Janeiro são marcadas pelas experiências com o tráfico de drogas. Neste sentido, é interessante ver o quanto este modo de vida pode oferecer poder, valorização, capital econômico, e de forma mais incisiva que em outros tipo de criminalidade, a volta ao tráfico, ou mesmo a volta ao morro como local de origem é uma tentação constante na vida dessas pessoas. Apesar da sedução das drogas e de suas aparentes possibilidades, há a certeza de que esta vida é curta, pois a morte ou o aprisionamento apresentam-se como o fim.

Para fazer frente a estas experiências, é preciso romper com esta vida e procurar novas possibilidades, geralmente voltando-se à família, à religião ou ao trabalho, precarizado, informal, mas honesto.

Em termos de esperanças e oportunidades, não há grandes expectativas, a não ser a conquista diária de mais espaço, melhores condições e, principalmente, de uma vida tranqüila, com dignidade. Sabendo que as grandes chances se foram, resta a construção de responsabilidades pessoais, a valorização por cuidar de si e dos outros, e neste aspecto, o programa e as redes constituídas a partir dele são fundamentais.

As análises de trajetória de vida dos egressos em Porto Alegre revelam similitudes e diferenças com as trajetórias de vida de egressos no Rio de Janeiro. Em primeiro lugar, assim como no Rio, as grandes esperanças resumem-se em conquistar algum tipo de renda, que possa satisfazer o sustento da família e da casa. Há, em função da experiência de vida, uma constatação de que não restam muitas possibilidades aos egressos, seja em função do estigma, seja em função da desqualificação educacional e profissional.

Com relação às trajetórias pós-prisionais, os egressos demonstram a importância da passagem pelos programas de apoio, pelo acesso a meios de sobrevivência, a experiências de trabalho, às redes de sociabilidade, mas também deixam claro que a conquista de cidadania e de inclusão, após a saída do cárcere é fruto, por um lado, de apoio externo, e de outro, de uma espécie de "conversão" (que pode ser religiosa, pelo trabalho, pela família), que implique em mudança de valores, criação de novas expectativas e principalmente, em assunção de responsabilidades e disposição para mudar de vida.

${ }^{19}$ CASTRO, Myriam de; et alli (1984). Preso um dia, preso toda a vida: a condição de estigmatizado do egresso penitenciário. Temas IMESC. Soc. Dir. Saude, v. 1, n. 2, p. 101. 
No entanto, apesar das dificuldades, é marcante na fala dos egressos a certeza de que a vida do crime, acessada em função ora de necessidade, ora de aventura e dinheiro fácil, ora de fatalidade, não leva a lugar algum que não seja a morte ou novamente a prisão, e isto não é mais vislumbrado como possibilidade para os egressos que buscam os programas de apoio em Porto Alegre.

A análise da situação pós-prisional e das chances de reinserção dos egressos está relacionada à passagem pela prisão, à constituição de redes de egressos, à religião e ao trabalho.

\section{As marcas da prisão: prisionização e estigma na visão dos egressos}

Os egressos, ao trazerem suas trajetórias de vida, referem sempre a passagem pela prisão como um ponto crucial. Em suas falas, a prisão é uma espécie de divisor de águas, a passagem de uma vida de emoção para uma vida de apatia. As memórias sobre a prisão dão conta do descaso, das violações de direitos, do sofrimento:

A vida que ele passa lá dentro, as dificuldades que ele encontra. Por exemplo, a pessoa fica analfabeto. Entra analfabeto e sai analfabeto, não tem como. Entra doente, ou então entra bom e sai doente. E com doenças de contaminação, entendeu? Se trabalhou, aquele direito que ele teve lá dentro, com dinheiro que ele podia ressarcir, fica em dificuldade, aqueles processos que ele trabalhou lá, somem (E1).

A visão que os egressos têm da saída da prisão e da existência restrita de programas de apoio deve-se à constatação da prisão como uma instituição a quem ninguém sobrevive.

Eles não têm projetos pra egressos porque eles pensam que nós não vamos sobreviver ao que eles fazem. Pensam que nós vamos morrer. Ou, quando sair de lá, nós não vamos querer mais nada na vida. E vamos ser farrapo humano (E2).

Sobre as consequências da passagem pela prisão, o egresso abaixo, utilizando uma linguagem própria do sistema penitenciário, explica as transformações sofridas pela personalidade de quem é encarcerado.

Vamos começar pelo cárcere. O cárcere ele está ali para disturbar a sua mente. Às vezes a pessoa chega lá nervoso, impaciente. Entendeu? Então, ele preso, ele vai se tornar uma pessoa mais calma, porque ele vai ser obrigada a se acostumar àquele ambiente. Entendeu? Então ele não vai poder ter pressa. Porque como é que ele vai ter pressa num lugar tão pequeno? Então disturba a mente. A pessoa sai como? Com arrogância, arrogante, que ele pensa que tudo ele pode fazer. Mas, na verdade, nós temos os nossos limites. Então quando ele sai lá de dentro, ele sai como um animal. 
Ele sai como uma pessoa que ele visa só aquele mundo ali dentro. Ele lidar com ódio, com pessoas que só querem o que é dele, pessoas que não têm amor a ninguém. Se ele não teve amor à própria pessoa dele, aqui fora, não se der valor, ele vai dar valor de quê? Então a pessoa tem, ali, de sobreviver no meio daquele montão de selvagens. Ele é mais um selvagem no meio dos outros selvagens. Então ele tem que ser o rei da selva pra sobreviver. Então ele vai criando o mundo dele. Vai se agarrando naquelas forças de vontade, que ele fica tirando, e só Deus mesmo que dá. E ele fica meio tonto, sai tonto de lá (E2).

A própria experiência de vida demonstra que, uma vez ingressando na vida do crime, a saída é difícil:

Agora tem uma coisa que as pessoas não sabem, mas olha, parece brincadeira, depois que o cara começa a matar, o cara pegar um gostinho e não quer mais. A coisa é tão boa - desculpe eu falar assim - a coisa é tão boa, que Deus não deu esse dom pra ninguém. Deus não falou: "Você pode matar." Mas o cara aprendeu que aquilo ali é uma coisa boa. O cara mata, se vicia naquilo. Aí tu tá pelo morro e vai indo (E3).

Junto aos efeitos deletérios da prisão, a marca do estigma é fundamental para a constituição do ex-presidiário como sujeito.

Principalmente no Rio de Janeiro, que as pessoas estão com medo mesmo da onda de violência. Quando tu chega numa pessoa que passou por um sistema penitenciário, tu associa logo à criminalidade, à violência. Então existe o preconceito, é fato, a gente tem uma grande dificuldade por conta disso. Então isso é uma coisa que a gente deixa bem claro (C1).

$\mathrm{Na}$ fala de egressos e agentes, a percepção do estigma aparece como o principal empecilho à obtenção de trabalho e reinserção social.

Tem sempre alguma coisa. Nós temos um estigma. Nós temos uma marca na testa de ex-presidiário. Se a gente arrumar um emprego aí na (universidade) da cidade, nós vamos conseguir trabalhar um mês. Porque daqui a um mês, eles já revirou a nossa ficha e já viu lá: ex-presidiário. O que vai dizer: sinto muito, seu serviço tá... mas estamos em contenção de despesa. Essa é a desculpa. Nós estamos com contenção de despesa, estamos mandando funcionário embora. Você que é o mais novo... Não vai te humilhar, dizer assim: tu é ex-presidiário. Isso ele não vai fazer. Mas vai te mandar embora (E1).

Percebe-se, pelos trechos acima, o quanto as representações sociais e identidades dos egressos estão marcadas pela vida criminal e prisional, marcas estas que levarão para o resto de suas vidas e que terão de ser levadas sempre em conta na hora de focalizá-los com projetos, políticas ou qualquer outro tipo de apoio. Como produto do pertencimento a um campo determinado, o universo pós-prisional, toda a constituição dos habitus dos egressos é dada por esta gama de capitais, experiências, que constroem suas trajetórias de vida. 
A prisão perdura como experiência para toda a vida, assim como a identidade de expresidiário Ihes acompanha, especialmente se atrelados a programas voltados a este público em específico. No entanto, é a partir dessa rede, como veremos mais adiante, que os egressos conseguem sobreviver e conquistar um mínimo de garantias que lhes permitirá sobreviver em uma sociedade tão reticente a esta categoria social.

\section{Egressos e religião: disciplinamento e controle social}

Levando-se em conta todas as trajetórias de vida dos egressos, verifica-se o quanto é necessário, em suas percepções de mundo, um controle que os permita o afastamento dos universos criminais e o papel da religião parece crucial na (re)construção de indivíduos que se veem "a perigo" quando em liberdade novamente. A religião também opera, e talvez este seja o seu principal "papel", explicando o porquê de seu sucesso em números de conversões, como um aglutinador social, estabelecendo-se uma nova rede, disponível para os mesmos indivíduos: aqueles que muitas vezes conviveram em uma mesma comunidade, em um mesmo universo criminal, compartilharam as mesmas experiências carcerárias e passam a acessar, de dentro e de fora da prisão, esta nova rede, que lhes garantirá uma trajetória pós-prisional.

A investigação empírica revelou que a presença das religiões pentecostais é muito marcante, havendo explicações sobrenaturais para o envolvimento criminal, ao mesmo tempo em que se deposita na religião todo o ganho longe da criminalidade. A conversão religiosa é entendida como salvação e o crime, visto como obra do demônio:

Jesus me libertou. Por causa de quê? O Diabo, o Lúcifer, era braço direito de Deus. Ele deixou entrar o orgulho no coração dele; ele queria sentar em cima da cadeira de Deus. Em cima de Deus ninguém senta. Deus jogou ele lá de cima aqui pra baixo. Lá em cima era anjo de luz; aqui em baixo, ele se transformou em anjo de treva, que é exú Caveira, pombagira, tranca-rua, é tudo demônio que caiu do céu. Aí, não pode fazer nada com Deus, faz nas pessoas que Deus criou. Entra no homem e faz nas pessoas que Deus criou (E4).

O homem está no mundo, cheirando, fumando e roubando; Jesus vai e tira o demônio dele. O demônio sai. Aí fica rodando, vem quando Jesus não tá. Se vê que o homem não está orando, não está jejuando, ele traz mais sete. O homem fica pior do que ele era. Entendeu? Então o mundo já é do diabo. O mundo é do demônio. O diabo está controlando a Terra. O mundo já é dele. Tá escrito aqui:... você conhece a palavra de Deus? (E4)

Para os egressos, como instrumento de controle social, a conversão religiosa revelase um meio de manutenção longe do crime, acabando por permitir o acesso a uma nova 
perspectiva de vida, com a inserção em uma nova rede social. A conversão é dada por uma busca por controle social, a partir do momento em que toma consciência da realidade prisional:

Não, desde que eu entrei na cadeia, foi na Igreja que Deus me resgatou, sabe assim, por causa que eu fiz um propósito, bah, é muita gente, é muita gente que não vale nada, muita gente ruim, muita gente má, que tem prazer de mata, que tem prazer de fazer os outro fica por baixo, poder de te poder, tá todo mundo ali sofrendo, como é que alguém que ser mais, às vezes tem uns lá lotado de cadeia, nem vão sair mais, vão morre ali dentro, e aí tem que calcular, porque por eles qualquer coisa serve, tá entendendo, igualmente eles vão ter que puxar trinta anos, daí se mata um ou dois, ou três, pra eles tanto faz, daí a gente tem que se cuida, né, sabe que a gente... Eu pensei pra mim, esse um ano e sete mês que eu fiquei lá preso poderia ta trabalhando, fiquei lá olhando pras parede, olhando pra cara de barbado (E5).

No entanto, é visível que a participação nessas religiões não tem um caráter emancipatório, senão uma atuação como redutor de danos ou gerenciador de vulnerabilidades.

\section{As redes de egressos: a constituição de sociabilidade pós-cárcere}

Os egressos, como grupo movido por determinadas características comuns, ao tornarem-se beneficiários dos programas, acabam constituindo novas relações ou retomando relações vindas das experiências prisionais, mas com uma nova perspectiva e um novo objetivo. Nas falas dos egressos percebe-se que a constituição de redes informais, compostas por eles e por alguns dos integrantes dos programas (sejam técnicos, funcionários ou mesmo coordenação, mas de uma maneira desvinculada das atuações gerais dos programas) permite desempenhar um papel de acompanhamento, com a formação de preocupações mútuas que serão fundamentais para a manutenção longe da criminalidade.

As redes de egressos acabam construindo um regramento ético e de confiança que, se rompido, implica grande frustração, reproduzindo a visão de prisionização e estigma contra a qual lutam o tempo todo. $O$ fato de os egressos verem os programas como espaços seus, de atuação e conquista de espaço, permite que se apropriem de sua causa, de uma maneira política, articulada, e lutem para a conquista dos objetivos propostos inicialmente pelas iniciativas, que passam a ser também objetivos seus.

Neste aspecto, a constituição dessas redes de sociabilidade garante a construção de uma percepção de grupo, não no sentido negativo, como grupo de ex-presidiários ou de ex-criminosos, mas como egressos, ou seja, pessoas que passaram por experiências 
duras, mas estão lutando para romper, individualmente e coletivamente, com suas trajetórias, seus habitus, e conquistar espaço e confiança - própria, perante os pares, o programa e, principalmente, a família e a sociedade.

\section{Egressos e trabalho}

A temática do trabalho é central na constituição das trajetórias pós-prisionais. Os egressos têm uma trajetória marcada pelo trabalho: em primeiro lugar, na sua visão, o envolvimento criminal é fruto de um abandono do ideal de trabalho, em função de uma vida mais fácil, de maior lucro e satisfação mais imediata, e que, para seu azar, deu errado. Quer queiram, quer não, a essencialização do trabalho é algo que lhes persegue desde o início de sua trajetória criminal, quando optaram por manter-se longe dele, passando pela vida carcerária, na qual, ou tiveram de trabalhar intramuros, ou quiseram trabalhar e não houve vagas, ou ainda "optaram" por desenvolver uma trajetória de "criminosos natos"20.

Ao sair da prisão, novamente o tema do trabalho revela-se chave: para a manutenção longe das grades, precisam trabalhar; para se reinserir, precisam trabalhar; para se sentirem cidadãos, precisam trabalhar.

É através do trabalho. Não tem como, tem que ser através do trabalho (E6).

É o ponto principal, né. É uma coisa que até hoje a gente pensa... e analisando... Como é que pode? É um projeto desse, a parte principal é quando se reúne a bola. Sem a bola não tem futebol, tem? É a mesma coisa que nós lidando com egresso. Sem trabalho, há desânimo. Vem aquele desânimo, pôxa... Quer dizer, a gente já faz por menos, em tirar o otimismo dele. Pelo contrário, procura fortalecer. Vamos esperar que (??) que vai clarear. Mas aqueles que não se assimila mais esse: "Vamos esperar que vai vir." Aí ou parte pra uma coisa à moda dele mesmo, ou voltar a inserir a criminalidade. E, no entanto, seria uma coisa importante, né, que esse projeto fosse virado só pra parte "vamos arrumar trabalho". Pôxa, já pensou? Como que não precisaria disso aqui, todo mundo empregado, tratando da sua família. Porque o cara sai daqui, vem aqui pra cá, nove horas, depende de um sacrifício conforme eu estava te explicando, o problema da condução. Sair da área dele pra vir pra cá, pro centro da cidade. E quando retornar pra lá, com a mão abanando, sem ter nada. Com três, quatro, cinco filhos dentro de casa. Às vezes mora debaixo da ponte, às vezes mora num abrigo. Às vezes é uma casa que ele toma aí dos outros. E, quer dizer, a pessoa tem que ter muita força de vontade pra suportar isso tudo. Né não? Não é mole não (E1).

No caso dos egressos, a saída da prisão e a busca de programas de apoio é pautada pela crença na reinserção pelo trabalho. No imaginário desses sujeitos, em muito

${ }^{20}$ RAMALHO, José Ricardo (2002). O mundo do crime. A ordem pelo avesso, $3{ }^{a}$ ed. São Paulo: IBCCRIM. 
reforçado pelos discursos judiciais e prisionais, há saída para aqueles que "forem bons e tiverem se arrependido", passando a viver de acordo com as regras sociais, como trabalhadores. O tipo de trabalho almejado pelos egressos é trabalho formal, 0 assalariado, que insere os trabalhadores no mercado, com todas as suas concessões e garantias.

[...] a maioria das mulheres, elas também têm os objetivos delas de vida. Elas também tentam. Elas vêm também com aquela esperança. Tem mulheres também que nunca trabalharam de carteira assinada. Então vem com aquele sonho, tipo do meu primeiro emprego. O sonho delas é querer um trabalho de carteira assinada. Mesmo que fosse até na limpeza, entendeu. Elas querem registrado (E7).

A expectativa, no entanto, fica só no imaginário. Para a maioria dos egressos, as novas experiências de trabalho tenderão a reproduzir as formas antigas, com 0 agravamento de que, se na época não eram ex-presidiários, hoje terão de lidar com o acréscimo do preconceito e da estigmatização, em uma sociedade ainda mais precarizada $^{21}$.

Ah, um dia eu trabalho de servente, amanhã leva outro dinheiro como pintor, ou oh, tu faz isso aí pra mim hoje, eu te cobro, 20, 30 pila, $R \$ 20$, por dia, trabalho dois dia na semana, depois não arruma nada, às vez numa semana tu não arruma nada também, aí te encarece (E8).

Uma oportunidade de trabalho é difícil. A primeira coisa que eles olham é, bah, esse aí vai fazer uma coisa errada, mas não, minha cabeça não tá assim, sabe, minha cabeça ta voltada pra minha família, pros meus filho, pra mim, principalmente (E9)

Tô morando com a minha família e desempregado, tô procurando emprego (E10).

Tu vai fazê um currículo, uma coisa, eles puxam a tua ficha, daí aparece tudo aquilo ali, e tu não pega o emprego, eles olham pra ti tu é adequado tudo, só que tu tá aqui (E8).

Apesar de todo este panorama, na análise de trajetória de muitos egressos, há sim, uma conquista de cidadania pelo trabalho. Há aqueles egressos que conseguiram obter trabalho, às vezes formalizado, às vezes, não, mas que, com esta obtenção, conseguiram reordenar suas vidas, passando a viver de acordo com as regras destinadas aos trabalhadores.

Eu prefiro um serviço de carteira assinada. Até porque se eu for vender alguma coisa, eu vou me derramar. Aí ela me deu aquele emprego lá. Fiquei lá três meses, depois saiu a minha vaga aqui. Vim pra cá e comecei a trabalhar. Eu não tinha nada. Hoje,

${ }^{21}$ ANTUNES, Ricardo (1999). Os sentidos do trabalho: ensaio sobre a afirmação e a negação do trabalho. São Paulo: Boitempo. 
graças a Deus, eu tenho uma casa, tenho os meus móveis direitinho. A casa está em obra, mas tenho a minha casa, tenho os meus moveizinhos direitinho. Já me visto direitinho. Não dá pra dizer que me visto bem, mas já me visto direitinho. Já posso me locomover pela cidade. E eu acho que é assim, olha, temos que ter força de vontade. Mas também temos que ter alguém pra nos amparar porque sozinho nós não vamos a lugar nenhum (E10).

Nestes casos, reproduz-se a perspectiva foucaultiana de que a prisão teria a função de transformar indivíduos sem propriedade em trabalhadores dóceis. Como a prisão não consegue tal feito, fica a cargo dos programas de apoio e as redes constituídas por egressos e instituições o papel de desestimular toda a forma de vida que não seja pautada pelos padrões tradicionais, que, para as camadas pobres, é o de trabalhador.

Depois que ele entra no projeto, como no caso que ele está explicando, teve três aqui que reincidiu ao crime novamente. Todos eles estão sofrendo aí, mas não estão passando pro lado do erro não. Estão aí aborrecidos, não tem trabalho, mas o que a gente pode fazer? Vai vender uma balinha ali, outra balinha lá (E1).

Sendo assim, se por um lado, a defesa da reinserção pelo trabalho parece anacrônica, perante um contexto social de trabalho escasso, por outro lado, acaba por permitir a assunção de valores de trabalho, que são fundamentais para a manutenção dos egressos longe do crime. E restará sempre, para aqueles que acreditam no potencial emancipatório do trabalho, o exemplo daqueles egressos (poucos casos) que deram certo, que conseguiram pelas vias tradicionais, de esforço e dedicação, a tão almejada conquista de reinserção e cidadania.

\section{Inclusão, exclusão ou controle social: quais as esperanças e oportunidades para os ex-presidiários?}

Tendo uma condição marcada pelo estigma, pelas dificuldades materiais, pela experiência da passagem prisional, questiona-se sobre as esperanças e oportunidades para egressos do sistema penitenciário. É importante perceber o quanto as trajetórias de vida dos egressos estão marcadas pelas experiências familiares e escolares que constituíram sua infância e adolescência. Salvo raras exceções, os históricos dos egressos são de desestrutura familiar, expulsão e fracasso escolar, além de péssimas condições econômicas, que resultaram em envolvimentos criminais.

A chegada ao crime é, na maioria das vezes, decorrente de necessidade, de oportunidades e aventura para sujeitos despidos de grandes expectativas e chances. $\mathrm{O}$ crime é, para as camadas populares, a possibilidade de subir na vida, ter acesso a bens 
de consumo, a mulheres, viver bem, desfrutando a vida. No entanto, selecionados desde cedo pelas malhas do sistema penal, as experiências de sucesso frustram-se pelo aprisionamento e pela constatação de que a prisão não é brincadeira.

Chama muito a atenção a fala dos egressos sobre uma tomada de consciência propiciada pela chegada à prisão. Muito embora não tenham privilegiado tanto as experiências prisionais em suas falas e as prováveis violações de direitos humanos sofridas no cárcere, e embora se saiba que a pena privativa de liberdade não cumpre com o previsto, não disciplina, não promove mudanças a não ser no sentido da prisionização, para estes egressos a prisão levou à constatação de que o fim para pobres envolvidos com a criminalidade é a morte ou o aprisionamento.

Aqui cabe mencionar mais uma vez a ideia de que os egressos desta pesquisa passaram por processos de "conversão", como uma ruptura de valores e assunção de novas responsabilidades, o que pode ocorrer pelo acesso à família, ao trabalho, ou à religião, mas que os leva a querer andar "no caminho do bem". Se a leitura crítica quanto ao papel desta conversão, em muitas vezes propiciada pelas religiões evangélicas pentecostais, dentro ou fora das prisões, é de que estas promovem controle social, na visão dos egressos o controle é visto como algo necessário e vislumbrado de forma a garantir que suas ações e atitudes irão dar-se no caminho "reto".

Havendo, pois, uma seletividade na busca pelos programas de apoio em função dessa disposição a "mudar de vida", é preciso questionar em que medida as iniciativas auxiliam nas trajetórias pós-prisionais dos egressos. Neste aspecto, é importante perceber que os programas apresentam-se como mediadores para as pequenas conquistas obtidas pelos egressos: acesso à cidadania formal, pelo porte de documentos; acesso a meios de sobrevivência, como alimentação, transporte, vestuário; acesso à saúde, pelo encaminhamento a redes públicas; acesso à escolarização, pelo encaminhamento à escola e a cursos profissionalizantes; e acesso ao trabalho. É claro que os programas, como bem demonstrado, atuam de forma precária, não propiciando todos os apoios para todos os egressos, sendo as concessões também seletivas. No entanto, há um grande envolvimento para satisfazer tais metas, como a criação de parcerias, de convênios, de redes de assistência.

Não é possível esquecer das condições precárias e dos limites encontrados dia a dia por cada ex-presidiário, na busca por trabalho, na discriminação pela ficha não-limpa, na temporariedade dos auxílios e apoios e da própria condição de egresso (como ex- 
presidiário detentor de direitos). Não é possível esquecer também que os programas de apoio desenvolvem possibilidades de controle dos egressos, seja pelo mapeamento de seu "paradeiro", seja pela constante averiguação quanto as suas informações judiciais. Apesar de tudo isso, só há chances com auxílio, só através das redes, da construção de visibilidade para este universo, através das concessões e da abertura de espaço que se poderá permitir que estes egressos deixem de ser homens infames.

É preciso refletir sobre o papel e o impacto dos programas de apoio na vida e nas trajetórias dos egressos, discutindo a respeito de suas esperanças e oportunidades. Analisando-se as trajetórias de vida dos egressos entrevistados percebe-se questões marcantes: são pessoas geralmente de origem pobre, com históricos de baixa escolarização e qualificação profissional, com famílias desestruturadas, ingressaram na criminalidade por necessidade, aventura, dinheiro fácil ou fatalidade, e tiveram, com a experiência prisional, uma constatação de que é preciso mudar de vida, para manter-se vivo, uma vez que para pobres envolvidos com a criminalidade só resta a morte ou a prisão.

Aqui cabe retomar a ideia de "conversão", sustentando que os egressos que chegam a programas de apoio passaram por um processo de troca de valores que os faz buscar uma nova possibilidade de vida, uma quebra de habitus, que os leve a uma nova trajetória. Para a absorção desses novos valores é necessário romper com expectativas propiciadas pelo mundo do crime, como poder, valorização, dinheiro, e reduzir as esperanças para pequenos ganhos diários, pequenas oportunidades.

\section{Conclusões}

Se a chegada aos programas de apoio dá-se em função de uma esperança por novas oportunidades, a passagem pelos programas, no entanto, pode resultar em ganhos e frustrações. Os programas não conseguem atender todas as demandas, há limites em sua atuação: nem todos conseguem acesso a trabalho, nem todos obtêm qualificação, no entanto, através dos programas os egressos conseguem acesso à cidadania formal, a assistências, como alimentação, roupa e transporte.

Não obstante, os programas apresentam-se como espaço de sociabilidade e as redes formadas a partir desta inserção serão fundamentais para a manutenção longe do crime, a redução da reincidência e a ampliação das pequenas chances. 
Enfim, pode-se concluir que, muito embora permaneçam como sujeitos estigmatizados, vivendo precariamente em uma sociedade excludente, após o apoio e a “conversão" voltam a ter esperanças e pequenas oportunidades que diminuirão o peso de sua condição de homens infames.

\section{Bibliografia}

Adorno, Sérgio (1989). Reincidência e reincidentes criminais em São Paulo: 1974 a 1985. RBCS, São Paulo, v.9, n. 3, p. 70 - 94, fev.

Adorno, Sérgio (1991). Sistema penitenciário no Brasil. Problemas e desafios. In: Revista Usp: São Paulo, março, abril, maio, pp. 65-78.

Adorno, Sérgio (2002). Exclusão socioeconômica e violência urbana. In: Sociologias. Porto Alegre: ano 4, n. 8, jul/ dez, pp. 84-135.

Alvarez, Marcos César (2004). Democracia, cidadania e políticas públicas de segurança. Anais da 56 a Reunião Anual da SBPC - Cuiabá, MT - Julho. Disponível em: http://www.nevusp.org/downloads/down123.pdf. Acesso em 25/03/2008.

Antunes, Ricardo (1999). Os sentidos do trabalho: ensaio sobre a afirmação e a negação do trabalho. São Paulo: Boitempo.

Argüello, Katie (2005). Do Estado social ao Estado penal: invertendo o discurso da ordem. Disponível em: http://www.cirino.com.br/artigos/Artigo\%20Katie.pdf Acesso em 10/11/2008.

Arretche, Marta (1995). A emergência e desenvolvimento do Welfare State: teorias explicativas. In: BIB, n. 39, 1‥ Semestre, p. 3-40.

Baratta, Alessandro (1999). Criminologia crítica e crítica do direito penal: introdução à sociologia do direito penal. 2. ed. Rio de Janeiro: Freitas Bastos: Instituto Carioca de Criminologia.

Barnes, J (1987). A. Redes sociais e processo político. In: Feldman-Bianco, Bela (Org.). Antropologia das sociedades contemporâneas: métodos. São Paulo: Global, p. 159 - 223.

Beato F., Cláudio (1999). Políticas Públicas de Segurança: equidade, eficiência e accountability. In: Reforma do Estado e Mudança Institucional no Brasil. Recife: Fundação Joaquim Nabuco e Editora Massangano, v.1, p. 335-365. Disponível em: http://www.crisp.ufmg.br/polpub.pdf. Acesso em 01/04/2008.

Bourdieu, Pierre (1980). Le sens pratique. Paris: Minuit.

Bourdieu, Pierre (1990). Coisas ditas. São Paulo: Brasiliense. 
Bourdieu, Pierre (2001). Meditações pascalianas. Rio de Janeiro: Bertrand Brasil.

Bourdieu, Pierre (1999). O capital social - notas provisórias. In: Nogueira, Maria Alice; Catani, Afrânio. Pierre Bourdieu: escritos de educação. 2. ed. Petrópolis: Vozes, p. 65 70.

Bourdieu, Pierre (2005). Esboço de auto-análise. São Paulo: Companhia das letras.

Bourdieu, Pierre (1997). Razones prácticas: sobre la teoría de la acción. Barcelona: Anagrama.

Bourdieu, Pierre (1996). A ilusão biográfica. In: In: AMADO, Janaína, FERREIRA, Marieta de Moraes. Usos e abusos da História Oral. Rio de Janeiro: Fundação Getúlio Vargas, p. 183-191.

Borés Espí, Josep García (2003). El impacto carcelario. In: BERGALLI, Roberto (coord.). Sistema Penal e problemas sociais. Valência: Tirant lo blanch.

BRASIL, Lei no 7210, de 13 de julho de 1984. Institui a lei de execução penal. Diário Oficial [da] República Federativa do Brasil, Brasília, DF, 13/07/1984.

BRASIL, Ministério da Justiça. Manual de convênios e projetos de reintegração social. Brasília: DEPEN, 2005.

BRASIL. Conselho Nacional De Política Criminal E Penitenciária. Resolução n. 014 de 1994.

BRASIL. Conselho Nacional De Política Criminal E Penitenciária. Resolução n. .5 de 1999.

BRASIL. Conselho Nacional De Política Criminal E Penitenciária. Resolução n.. 4 de 2001.

BRASIL. Conselho Nacional De Política Criminal E Penitenciária. Resolução n. 915 de 2003.

Camargo, José Marcio (2004). Política social no Brasil: prioridades erradas, incentivos perversos. In: São Paulo em Perspectiva, vol.18, n.2. São Paulo: Abril./Junho, p. 68-77.

Castel, Robert (2001). As metamorfoses da questão social: uma crônica do salário, 3a . ed. Petrópolis: Vozes, $611 \mathrm{p}$.

Castro, Myriam de; et alli (1984). Preso um dia, preso toda a vida: a condição de estigmatizado do egresso penitenciário. Temas IMESC. Soc. Dir. Saude, v. 1, n. 2, p. 101107.

Christie, Nils (2003). L'industrie de la Punition: prision et politique pénale em occident. Paris: Autrement. 
Delmas-Marty, Mireille (2004). Os grandes sistemas de política criminal. Barueri: Manole, 2004.

Downes, David (2007). A economia penal brutal: o encarceramento em massa nos EUA: uma perspectiva européia. In: GIDDENS, Anthony (org.). O debate global sobre a Terceira Via. São Paulo: UNESP, 2007, p. 297-316.

Draibe, Sônia e Henrique, Wilnês (1988). "Welfare State", crise e gestão da crise: um balanço da literatura internacional. Revista Brasileira de Ciências Sociais. São Paulo: ANPOCS, 2006, vol. 5, $n^{\circ}$ 6: 53-78, fevereiro. Acesso em 14/07/2008. Disponível em: http://www.anpocs.org.br/portal/publicacoes/rbcs $0006 /$ rbcs06 $04 . h t m$

Draibe, Sônia (2007). Estado de Bem-Estar, desenvolvimento econômico e cidadania: algumas lições da literatura contemporânea. In: HOCHMAN, Gilberto; ARRETCHE, Marta;

Marques, Eduardo. Políticas públicas no Brasil. Rio de Janeiro: Fiocruz, p. 27-64.

ESPING-ANDERSEN, Gosta (1991). As três economias políticas do Welfare State. In: Lua Nova, n. 24, setembro, p. 85-116.

Esping-Andersen, Gosta (1995). O futuro do Welfare State na nova ordem mundial. In: Lua Nova, n. 35, p. 73-111.

Faleiros, Vicente de Paula (2006). Inclusão social e cidadania. 32nd. Internacional Conference on Social Welfare. Brasília. Disponível em: http://www.icsw.org/globalconferences/Brazil2006/papers/vicente faleiros.pdf Acesso em 05/11/2008.

Foucault, Michel (1999). A verdade e as formas jurídicas, Rio de Janeiro: Nau.

Foucault, Michel (1996). La vida de los hombres infames. La Plata: Caronte Ensayos.

Foucault, Michel (2003). Ditos e escritos IV. Estratégia, poder-saber. Rio de Janeiro: Forense Universitária.

Foucault, Michel (2002). Os anormais. São Paulo: Martins Fontes.

Foucault, Michel (1996). Vigiar e Punir. História da violência nas prisões, 14a ed.. Petrópolis: Vozes.

Garland, David (2005). El cultura del control. Barcelona: Editorial Gedisa.

Garland, David (1993). Punishment and modern society. Chicago: Chicago University Press.

Garland, David; Sparks, Richard (2000). Criminology and social theory. Oxford: Oxford UK.

Goffmann, Erving (1988). Estigma: Notas sobre a manipulação da identidade deteriorada. 4. ed. Rio de Janeiro: LTC. 
Höfling, Eloísa de Mattos (2001). Estado e políticas (públicas) sociais. In: Cadernos Cedes, ano XXI, n. 55, novembro, p. 30-41.

Liebling, Alison; Maruna, Shadd (2005). The effects of Imprisonment. Londres: Willan Publishing.

Marteleto, Regina Maria \& SILVA, Antonio Braz de Oliveira (2004). Redes e capital social: o enfoque da informação para o desenvolvimento local. Ciência da Informação, Brasília, v. 33 , n. 3, p. 41-49, set/dez.

Moraes, Pedro Rodolfo Bode de (2005). Punição, encarceramento e construção de identidade profissional entre agentes penitenciários. São Paulo: IBCCRIM.

ONU, Organizações das Nações Unidas (1977). Regras Mínimas para o Tratamento dos Reclusos. Disponível em: http://pfdc.pgr.mpf.gov.br/legislacao-pfdc/docs sistemprisional/regras minimas.pdf. Acesso em 29/09/2008.

Petersilia, Joan (2003). When prisioners come home: parole and prisioners reentry. Oxford.

Quiroga, Ana Maria (2005). Religiões e Prisões no Rio de Janeiro: presença e significados. In: Comunicações do ISER, Rio de Janeiro, v. 61, n. 61, p. 13-21.

Ramalho, José Ricardo (2002). O mundo do crime. A ordem pelo avesso, $3^{a}$ ed. São Paulo: IBCCRIM.

Rodrigues, Gilse (2005). Transgressão, controle social e religião: um estudo antropológico sobre as práticas religiosas na penitenciária feminina do estado do rio grande do sul.

Debates do NER, Porto Alegre, Ano 6, N. 8, P. 9-20, Jul./Dez.

Salla, Fernando (1995). Sobre o trabalho nas prisões. In: Revista do Conselho Nacional de Política Criminal e Penitenciária. Brasília, 1 (5), pp. 23 - 40, jan. / jun.

Salla, Fernando (2006). A pesquisa sobre as prisões: um balanço preliminar. In: Koener, Andrei (org). História da Justiça Penal no Brasil. São Paulo: IBCCRIM, p. 107-127.

Salla, Fernando (2003). Os impasses da democracia brasileira: o balanço de uma década de políticas para as prisões no Brasil. In: Lusotopie, p. 410-435. Disponível em: http://www.lusotopie.sciencespobordeaux.fr/salla2003.pdf. Acesso em 06/04/2008.

Souza, Celina (2007). Estado da arte da pesquisa em políticas públicas. In: Hochman, Gilberto; Arretche, Marta; Marques, Eduardo. Políticas públicas no Brasil. Rio de Janeiro: Fiocruz, p. 65-86.

Wacquant, Loïc (2001). As prisões da miséria. Rio de Janeiro: Jorge Zahar.

Wacquant, Loïc (2003). Punir os pobres. A nova gestão da miséria nos Estados Unidos. Rio de Janeiro: Revan. 
Xiberras, Martine (1996). As teorias da exclusão: para uma compreensão do imaginário do desvio. Lisboa: Instituto Piaget.

Young, Jock (2002). A sociedade excludente. Rio de Janeiro: Revan: Instituto Carioca de Criminologia. 